\title{
Documentation of guideline adherence in antenatal records across maternal weight categories: a chart review
}

\author{
Sarah D McDonald ${ }^{1 *}$, Clea A Machold ${ }^{2}$, Laura Marshall ${ }^{3}$ and Dawn Kingston ${ }^{4}$
}

\begin{abstract}
Background: Documentation in medical records fulfills key functions, including management of care, communication, quality assurance and record keeping. We sought to describe: 1) rates of standard prenatal care as documented in medical charts, and given the higher risks with excess weight, whether this documentation varied among normal weight, overweight and obese women; and 2) adherence to obesity guidelines for obese women as documented in the chart.

Methods: We conducted a chart review of 300 consecutive charts of women who delivered a live singleton at an academic tertiary centre from January to March 2012, computing Analysis of Variance and Chi Square tests.

Results: The proportion of completed fields on the mandatory antenatal forms varied from 100\% (maternal age) to $52.7 \%$ (pre-pregnancy body mass index). Generally, documentation of care was similar across all weight categories for maternal and prenatal genetic screening tests, ranging from 54.0\% (documentation of gonorrhea/chlamydia tests) to 85.0\% (documentation of anatomy scan). Documentation of education topics varied widely, from fetal movement in almost all charts across all weight categories but discussion of preterm labour in only $20.6 \%, 12.7 \%$ and $13.4 \%$ of normal weight, overweight and obese women's charts $(p=0.224)$. Across all weight categories, documentation of discussion of exercise, breastfeeding and pain management occurred in less than a fifth of charts.

Conclusion: Despite a predominance of excess weight in our region, as well as increasing perinatal risks with increasing maternal weight, weight-related issues and other elements of prenatal care were suboptimally documented across all maternal weight categories, despite an obesity guideline.
\end{abstract}

Keywords: Antenatal medical records, Documentation, Guideline adherence, Obesity, Prenatal care

\section{Background}

Obesity during pregnancy is now highly prevalent, and is recognized by care providers as an important health issue [1] due to associated complications. Obesity affects at least 16-19\% of pregnant women in the United Kingdom [2], and 11\% [3] - 40\% [4] of pregnant women in America, with overweight affecting an additional 12\% [5] -38\% [4]. Obese women are at increased risks of both maternal complications (including excess weight gain and gestational

\footnotetext{
*Correspondence: mcdonals@mcmaster.ca

'Division of Maternal-Fetal Medicine, Departments of Obstetrics \& Gynecology and Diagnostic Imaging and Clinical Epidemiology \& Biostatistics, McMaster University, 1280 Main St. West, HSC 3N52B, Hamilton, ON L8S4K1, Canada

Full list of author information is available at the end of the article
}

diabetes) [6] and fetal complications (such as anomalies including neural tube defects and preterm birth) [7].

The increased risk of complications in obese women is particularly concerning as outside of pregnancy obese women have been found to be less likely to seek or receive key elements of health care including screening [8-10].

To try to facilitate high quality health care, standardized Antenatal Record forms are mandatory in many jurisdictions including in the province of Ontario, where this research was conducted [11]. Additionally, recommendations for care of obese women have been summarized in national guidelines by multiple organizations, including the Centre for Maternal and Child Enquiries jointly with the Royal College of Obstetricians and Gynaecologists (CMA $\mathrm{CE} / \mathrm{RCOG})$, the American College of Obstetrics and 
Gynecology (ACOG) and the Society of Obstetricians and Gynecologists of Canada (SOGC) $[2,12,13]$. We sought to determine documentation of adherence to recommendations for standard prenatal care for women across all weight classes, and given the higher perinatal risks in women of excess weight, whether this documentation varied among normal weight, overweight and obese women. Our secondary objective, in the case of obese women, was to determine the degree of documented adherence to obesity guidelines $[12,13]$.

\section{Methods}

We conducted a chart review. We included all women who gave birth to a live singleton infant at an academic tertiary care centre, McMaster University Medical Centre in Hamilton, Ontario, Canada between January 2012 and March 2012 and whose charts included the Ministry of Health mandated Antenatal Records. We reviewed 300 consecutive charts meeting inclusion criteria as a convenience sample.

Our research questions were: (1a) What proportion of charts have documentation of standard prenatal care? 1b) Compared to women with normal weight, do overweight or obese women have similar documentation of standard prenatal care; and (2) In the case of obese women, does their documented antenatal care reflect the specific recommendations related to weight in the guideline on obesity during pregnancy [13]?

We hypothesized that documentation would be suboptimal across all weight categories in terms of standard prenatal care but that certain types of screening, such as Papanicolaou tests and gonorrhea and chlamydia tests might not be as frequent in obese women due to technical difficulties. Secondly, we hypothesized that obese women would have more complete documentation of weight-related issues, reflecting the guideline on obesity during pregnancy [13].

With regards to outcomes related to standard prenatal care, we examined the documentation of the following components in the antenatal record:

i. maternal screening: pre-pregnancy weight, height and BMI calculation, weight at subsequent visits, Papanicolaou test, gonorrhea and chlamydia tests, and gestational diabetes, and Group Beta Streptococcus (GBS) status;

ii. prenatal genetic screening: the Integrated Prenatal Screen (IPS), First Trimester Screening (FTS) or Maternal Serum Screening (MSS) or chorionic villus sampling or amniocentesis, and first trimester [14] and second trimester ultrasound scans, and

iii. counseling and education on 21 'discussion topics' addressing subjects such as exercise, fetal movement, preterm labour, prenatal classes, birth plans, pain management, and breastfeeding.
With regards to outcomes related to prenatal care specific to obese women, we examined the following components of documentation in the Antenatal Record of the prenatal care portion of the obesity guidelines [13]:

i. body mass index (BMI) - calculated from pre-pregnancy height and weight;

ii. counseling about weight gain, nutrition, and food choices;

iii. counseling about increased risk of congenital abnormalities, and appropriate screening;

iv. counseling about increased risk for medical complications (such as gestational diabetes) and that regular exercise during pregnancy may help to reduce some of these risks.

We focused on the prenatal care portion of the SOGC guidelines on obesity, [13] which are very similar to the CMACE/RCOG guidelines [2] and the ACOG guidelines [12] as we were interested in prenatal care (not intrapartum care). Additionally, many of these items already appear on the Ministry of Health-mandated Antenatal Records and hence had the highest likelihood of being documented. All four of the topics that the guideline [13] emphasized for the prenatal care of obese women (calculation of prepregnancy BMI, counseling about weight gain, counseling about complications such as gestational diabetes, and counseling about congenital anomalies) are also part of standard prenatal care for all weight classes of women.

As per the Institute of Medicine Guidelines (also adopted by Health Canada), $[15,16]$ we classified women according to the World Health Organization pre-pregnancy body mass index (BMI) weight categories (underweight: BMI $<18.5 \mathrm{~kg} / \mathrm{m}^{2}$, normal weight: BMI $18.5-24.9 \mathrm{~kg} / \mathrm{m}^{2}$, overweight: BMI $25.0-29.9 \mathrm{~kg} / \mathrm{m}^{2}$, and obese: BMI $\geq 30 \mathrm{~kg} / \mathrm{m}^{2}$ ). If the care provider had not calculated BMI, then we calculated it based on the height reported in the chart. When the height was not recorded, we used weight alone as in previous studies to categorize women as overweight [17] $(70-89 \mathrm{~kg})$ and obese $[13,17,18](\geq 90 \mathrm{~kg})$.

We reviewed the hospital charts of the patients, consisting of both information gathered in hospital as well as the care providers' office charts which are faxed to the hospital typically in the later third trimester. Health care providers in Ontario record antenatal information on governmentmandated Ministry of Health forms called Antenatal Record 1 and 2, which contain similar fields to the National Institute for Health Care Excellence (NICE) antenatal care pathways [19] and the ACOG Antepartum Record [20]. The first page of the Antenatal Record contains information on demographics of the mother and partner including occupation, education and marital status, the dating of the pregnancy, medical history and physical exam, initial laboratory investigations, and prenatal genetic investigations. 
The second page of the Antenatal Record contains identified risk factors, information on each visit (including the date and number of weeks gestation, weight, blood pressure, proteinuria, fetal heart rate, and comments), ultrasound results, additional Lab Investigations including Glucose Challenge Test (GCT), Glucose Tolerance Test (GTT), plan of management and a list of 21 discussion topics. The 21 discussion topics are generally addressed throughout the course of the latter half of the pregnancy. Results from any tests are to be recorded on the mandatory Antenatal Records.

For all outcomes, we reviewed the Antenatal Records as well as the entire hospital chart (including the initial referral letter and discharge summary). A trained research assistant used a standardized data collection form to abstract data. The Hamilton Health Sciences/McMaster University Faculty of Health Sciences Research Ethics Board approved the study prior to its initiation (REB Project \# 12-315-C).

We first generated descriptive statistics (proportions, means and standard deviations) of the sample characteristics and outcomes. To determine if differences in the outcomes were evident across our 3 groups of interest women with normal weight, overweight and obesity - we used Analysis of Variance (ANOVA) for continuous variables and Chi Square tests for proportions. In accordance with our multiple outcomes, statistical significance was set at $\mathrm{p}<0.001$. In a post hoc exploratory analysis, we examined whether the degree of documentation varied by the type of care provider, since midwifery visits generally last longer [21-23].

This study was approved by the Hamilton Health Sciences/McMaster University Faculty of Health Sciences Research Ethics Board, Project \# 12-315-C, June 21, 2012.

\section{Results}

In our audit of 300 consecutive charts of women who gave birth at our academic tertiary care centre over a 3month period (Table 1), the proportion of completed fields on the Ministry of Health mandated antenatal forms varied from $100 \%$ for maternal age to $53 \%$ for BMI. Descriptive statistics are shown in Table 1. The mean maternal age at the time of first visit was 29.9 years (SD 5.8), the majority of women were Caucasian (58\%), either married or in a common-law relationship (77\%) and worked outside the home (60\%).

Just over half of women had BMI recorded by the care provider (53\%) in the Antenatal Record, while 40\% had pre-pregnancy height and weight recorded without BMI being calculated. Additionally, there were 19 women for whom height was not recorded. Among these 19 women, weight was recorded for 8 in the first trimester, 7 in the second trimester, and 4 in the third trimester while for 2 there was no weight available anywhere in the chart. According to pre-pregnancy BMI, 42\% were
Table 1 Baseline characteristics of the study sample

\begin{tabular}{lr}
\hline Variable & $\begin{array}{r}\text { Number and proportion (\%) of } \\
\text { study sample unless otherwise } \\
\text { indicated }\end{array}$ \\
\hline Maternal age & $29.9(5.8)$ \\
Years, mean (SD) & $231(77.0 \%)$ \\
$<35$ years & $69(23.0 \%)$ \\
$\geq 35$ years & \\
Ethnicity & $174(58.0 \%)$ \\
Caucasian & $64(21.3 \%)$ \\
Other & $59(19.7 \%)$ \\
Blank & $3(1.0 \%)$ \\
Not legible & \\
Marital status & $230(76.7 \%)$ \\
Married or common-law & $36(12.0 \%)$ \\
Single & $33(11.0 \%)$ \\
Blank & $1(0.3 \%)$ \\
Unclear (not legible or discrepant & \\
documentation) & \\
Education & \\
Post-secondary & $156(52.0 \%)$ \\
Secondary or less & $57(19.0 \%)$ \\
Blank & $83(27.7 \%)$ \\
Not legible & $4.3 \%)$
\end{tabular}

\section{Occupation}

Work outside the home

$180(60.0 \%)$

Homemaker

$50(16.7 \%)$

Student

$17(5.7 \%)$

Unemployed

$19(6.3 \%)$

Blank

$24(8.0 \%)$

Unclear (not legible or discrepant documentation)

$10(3.3 \%)$

Currently smoking

$44(14.7 \%)$

Pregnancy history

First time giving birth

$86(28.7 \%)$

One or more previous births

$214(71.3 \%)$

\section{BMI classification}

Underweight $\left(\mathrm{BMI} \leq 18.4 \mathrm{~kg} / \mathrm{m}^{2}\right)$

$11(3.7 \%)$

Normal weight (BMI 18.5-24.9

$\mathrm{kg} / \mathrm{m}^{2}$ )

$126(42.0 \%)$

Overweight (BMI $25.0-29.9 \mathrm{~kg} / \mathrm{m}^{2}$ )

$79(26.3 \%)$

or when height unavailable

weight of 70-89 kg [17]

(most pre-pregnancy)

Obese $\left(\mathrm{BMI} \geq 30 \mathrm{~kg} / \mathrm{m}^{2}\right)$ or when

height unavailable weight

of $\geq 90 \mathrm{~kg}[13,17,18]$

(most pre-pregnancy)

No weight recorded anywhere on chart 
normal weight, $26 \%$ were overweight $27 \%$ were obese, while only $4 \%$ were underweight.

Outcomes for the whole study population are shown in Table 2, and additionally are compared by weight category. Documentation of antenatal care components varied by outcome, with almost all women having weight recorded at every visit (92\%), but only 54\% of charts having documentation of swabbing for gonorrhea and chlamydia. Overall, documentation of care was similar amongst normal weight, overweight and obese women in terms of weight recorded prenatally and at antenatal visits, performance of Papanicolau testing, gonorrhea and chlamydia screening, first ultrasound performed during the first trimester (as per another SOGC guideline) [14] , prenatal genetic screening, swabbing for group B streptococcus and education topics .

The extent to which education topics were documented as being covered varied widely by topic. For instance, while education on fetal movement was documented in almost all charts, discussion of preterm labour was documented in only $20.6 \%, 12.7 \%$ and $13.4 \%$ of normal weight, overweight and obese women's charts $(p=0.22)$. Although a discussion of a birth plan was documented in more than a third of charts, less than a fifth of charts documented discussions related to prenatal classes, breastfeeding, and pain management.

Less than $20 \%$ of women across all weight categories had documentation of a recommendation for a particular amount of weight gain $(13.7 \%, 8.9 \%$, and $17.1 \%$ of normal weight, overweight, and obese women, respectively, $\mathrm{p}=0.26$ ).

The majority of women had documentation of a second trimester ultrasound performed for anatomical assessment between $18-22$ weeks, with $86.5 \%, 87.3 \%$ and $79.3 \%$ of normal weight, overweight and obese women's charts noting this $(\mathrm{p}=0.27)$.

Documentation of screening for gestational diabetes was suboptimal, occurring in $71 \%, 76 \%$ and $62 \%$ of normal weight, overweight, and obese women's charts ( $p=0.086)$.

Exercise was rarely checked off in the discussion topics or written anywhere in the chart (occurring in only $13.5 \%, 17.7 \%$, and $7.3 \%$ of normal weight, overweight, and obese women's charts, $\mathrm{p}=0.14$ ).

In a post hoc exploratory analysis, we noted that charts of women under exclusive midwifery care generally had higher proportions of documentation of discussion topics, but also had higher rates of documentation indicating that swabbing for gonorrhea or chlamydia was not done, and that genetic screening was declined or too late to be offered to the woman (data not shown).

\section{Discussion}

Documentation in prenatal records fulfills key functions, including patient care management, communication, quality assurance and record keeping for legal purposes
[24]. We found suboptimal documentation in many areas of prenatal care and the observed rates of documentation did not increase across weight categories despite both increasing perinatal risks, and guidelines specifically addressing recommendations related to weight in obese women $[12,13]$.

Just over half of all women had documentation of prepregnancy BMI, despite the fact that the government mandated Antenatal Records contain a space specifically for it, and it is a specific recommendation of the obesity guidelines that it be calculated $[12,13]$. Moreover, prenatal weight gain guidelines are based on pre-pregnancy BMI $[15,16]$ and hence cannot be followed accurately without knowledge of pre-pregnancy BMI. Additionally, counseling about weight gain is an explicit recommendation in the obesity guidelines [12,13] although we found that only a minority of charts either overall or in obese women contained documentation of a recommendation of weight gain. Low rates are concerning given that a lack of counseling about weight gain is associated with inappropriate gestational weight gain, both inadequate and excessive, compared to having received counseling by a health care provider [25]. We are not aware of other studies that examined documentation of adherence to guidelines according to weight category, apart from a single study that examined only gestational weight gain and not the additional outcomes. This study, located in a Massachusetts tertiary care center, found even lower rates (only 4.6\%) of documentation of pre-pregnancy BMI in the antenatal records [26].

Previous work has shown that the creation and dissemination of a guideline does not equate with implementation [27]. For instance, only 50\% of Australian antenatal care providers correctly identified the BMI categories and only $32 \%$ were aware of the weight guidelines [1]. Barriers to adherence to guidelines include lack of awareness of guidelines, lack of motivation, lack of time and lack of outcome expectancy (belief that the desired outcome will be achieved) [28,29]. Strategies for overcoming barriers to knowledge translation at an individual practitioner level, audit and feedback, reminders and multifaceted strategies have been shown to be particularly effective in obstetrics literature [30]. At a system level include: ensuring liberal access to internet facilities including databases tailored to each particular specialty at point of care (if the barrier consisted of poor access to best evidence), and at a local workplace level of having regular evidence-based rounds and mentors including change mentors, innovators and educators (if the barrier was lack of knowledge) [31]. However, in our study, the issue is unlikely to be one of inadequate knowledge translation concerning the guideline, given that in previous research [32], the same practitioners as those whose charts were included in this study, generally 
Table 2 Outcomes in whole study sample

\begin{tabular}{|c|c|c|c|c|c|}
\hline Variable & $\begin{array}{l}\text { Number and } \\
\text { proportion (\%) } \\
\text { of study sample }\end{array}$ & $\begin{array}{l}\text { Number and } \\
\text { proportion (\%) for } \\
\text { normal weight } \\
\text { (BMI = 18.5-24.9) }\end{array}$ & $\begin{array}{l}\text { Number and proportion } \\
\text { (\%) for overweight } \\
\left(\mathrm{BMI}=25.0-29.9 \mathrm{~kg} / \mathrm{m}^{2}\right)\end{array}$ & $\begin{array}{l}\text { Number and } \\
\text { proportion }(\%) \text { for } \\
\text { obese }\left(B M I \geq 30 \mathrm{~kg} / \mathrm{m}^{2}\right)\end{array}$ & $P$ value \\
\hline & $N=300^{1}$ & $N=126$ & $N=79$ & $N=82$ & N/A \\
\hline $\begin{array}{l}\text { Pre-pregnancy BMI } \\
\text { recorded in chart }\end{array}$ & 159 (53.0\%) & $71(56.3 \%)$ & $42(53.2 \%)$ & $39(47.6 \%)$ & 0.71 \\
\hline $\begin{array}{l}\text { Weight recorded at } \\
\text { antenatal visits }\end{array}$ & & & & & 0.88 \\
\hline Always & 277 (92.3\%) & $115(91.3 \%)$ & $74(93.7 \%)$ & 77 (93.9\%) & \\
\hline Never & $4(1.3 \%)$ & $1(0.8 \%)$ & $0(0.0 \%)$ & $1(1.2 \%)$ & \\
\hline Sometimes & $19(6.3 \%)$ & $10(7.9 \%)$ & $5(6.3 \%)$ & $4(4.9 \%)$ & \\
\hline $\begin{array}{l}\text { Documented recommendation } \\
\text { of weight gain }\end{array}$ & $41(13.7 \%)$ & $20(13.7 \%)$ & $7(8.9 \%)$ & $14(17.1 \%)$ & 0.26 \\
\hline $\begin{array}{l}\text { Obesity correctly identified } \\
\text { a risk factor }\end{array}$ & $76 / 82(92.7 \%)$ & $0(0.0 \%)$ & $4(5.1 \%)$ & $76(92.7 \%)$ & N/A \\
\hline Papanicolaou test & & & & & 0.87 \\
\hline Documented within last year & $197(65.7 \%)$ & $84(66.7 \%)$ & $53(67.1 \%)$ & $52(63.4 \%)$ & \\
\hline Documented greater than 1 year ago & $28(9.3 \%)$ & $10(7.9 \%)$ & $6(7.6 \%)$ & $11(13.4 \%)$ & \\
\hline $\begin{array}{l}\text { Not documented anywhere } \\
\text { in chart }\end{array}$ & $54(18.0 \%)$ & $24(19.0 \%)$ & $14(17.7 \%)$ & $13(15.9 \%)$ & \\
\hline Date not legible & $21(7.0 \%)$ & $8(6.3 \%)$ & $6(7.6 \%)$ & $6(7.3 \%)$ & \\
\hline Gonorrhea and chlamydia tests & & & & & 0.67 \\
\hline Documented as swabbed & $162(54.0 \%)$ & $70(55.6 \%)$ & $44(55.7 \%)$ & $42(51.2 \%)$ & \\
\hline Documented as not swabbed & $6(2.0 \%)$ & $4(3.2 \%)$ & $0(0.0 \%)$ & $2(2.4 \%)$ & \\
\hline $\begin{array}{l}\text { Not documented anywhere } \\
\text { in chart }\end{array}$ & $131(43.7 \%)$ & $51(40.5 \%)$ & $35(44.3 \%)$ & $38(46.3 \%)$ & \\
\hline Not legible & $1(0.3 \%)$ & $1(0.8 \%)$ & $0(0.0 \%)$ & $0(0.0 \%)$ & \\
\hline Prenatal genetic screening ${ }^{3}$ & & & & & 0.37 \\
\hline Documented accepted ${ }^{5}$ & $153(51.0 \%)$ & $68(54.0 \%)$ & $32(40.5 \%)$ & $46(56.1 \%)$ & \\
\hline $\begin{array}{l}\text { Documented declined or } \\
\text { too late for tests }\end{array}$ & $90(30.0 \%)$ & $35(27.8 \%)$ & 31 (39.2\%) & $21(25.6 \%)$ & \\
\hline $\begin{array}{l}\text { No results or offer documented } \\
\text { anywhere in chart }\end{array}$ & $35(11.7 \%)$ & $13(10.3 \%)$ & $10(12.7 \%)$ & $11(13.4 \%)$ & \\
\hline $\begin{array}{l}\text { Unclear (documented as both accepted } \\
\text { and declined or too late }{ }^{4} \text { ) }\end{array}$ & $22(7.3 \%)$ & $10(7.9 \%)$ & $6(7.6 \%)$ & $4(4.9 \%)$ & \\
\hline \multicolumn{6}{|l|}{ First ultrasound scan } \\
\hline Documented in first trimester & $212(70.7 \%)$ & $89(70.6 \%)$ & $54(68.3 \%)$ & $60(73.2 \%)$ & 0.09 \\
\hline $\begin{array}{l}\text { Second trimester } 18-22 \text { week ultrasound } \\
\text { scan for anatomy }\end{array}$ & $255(85 \%)$ & 109 (86.5\%) & $69(87.3 \%)$ & $65(79.3 \%)$ & 0.27 \\
\hline $\begin{array}{l}\text { No ultrasounds documented anywhere in } \\
\text { chart }\end{array}$ & $8(2.7 \%)$ & $5(4.0 \%)$ & $0(0.0 \%)$ & $2(2.4 \%)$ & \\
\hline $\begin{array}{l}\text { Unclear (dates not legible or discrepant } \\
\text { documentation }{ }^{5} \text { ) }\end{array}$ & $1(0.3 \%)$ & $1(0.8 \%)$ & $0(0.0 \%)$ & $0(0.0 \%)$ & \\
\hline $\begin{array}{l}\text { Gestational diabetes testing }{ }^{2} \\
\text { (Glucose challenge test and/or } \\
\text { Glucose tolerance test) }\end{array}$ & & & & & 0.09 \\
\hline Documented as completed & 207 (69.0\%) & $90(71.4 \%)$ & $60(75.9 \%)$ & $51(62.2 \%)$ & \\
\hline Documented as not completed & $28(9.3 \%)$ & $15(11.9 \%)$ & $6(7.6 \%)$ & $6(7.3 \%)$ & \\
\hline Not documented anywhere in chart & $65(21.7 \%)$ & $21(16.7 \%)$ & $13(16.5 \%)$ & $25(30.5 \%)$ & \\
\hline
\end{tabular}


Table 2 Outcomes in whole study sample (Continued)

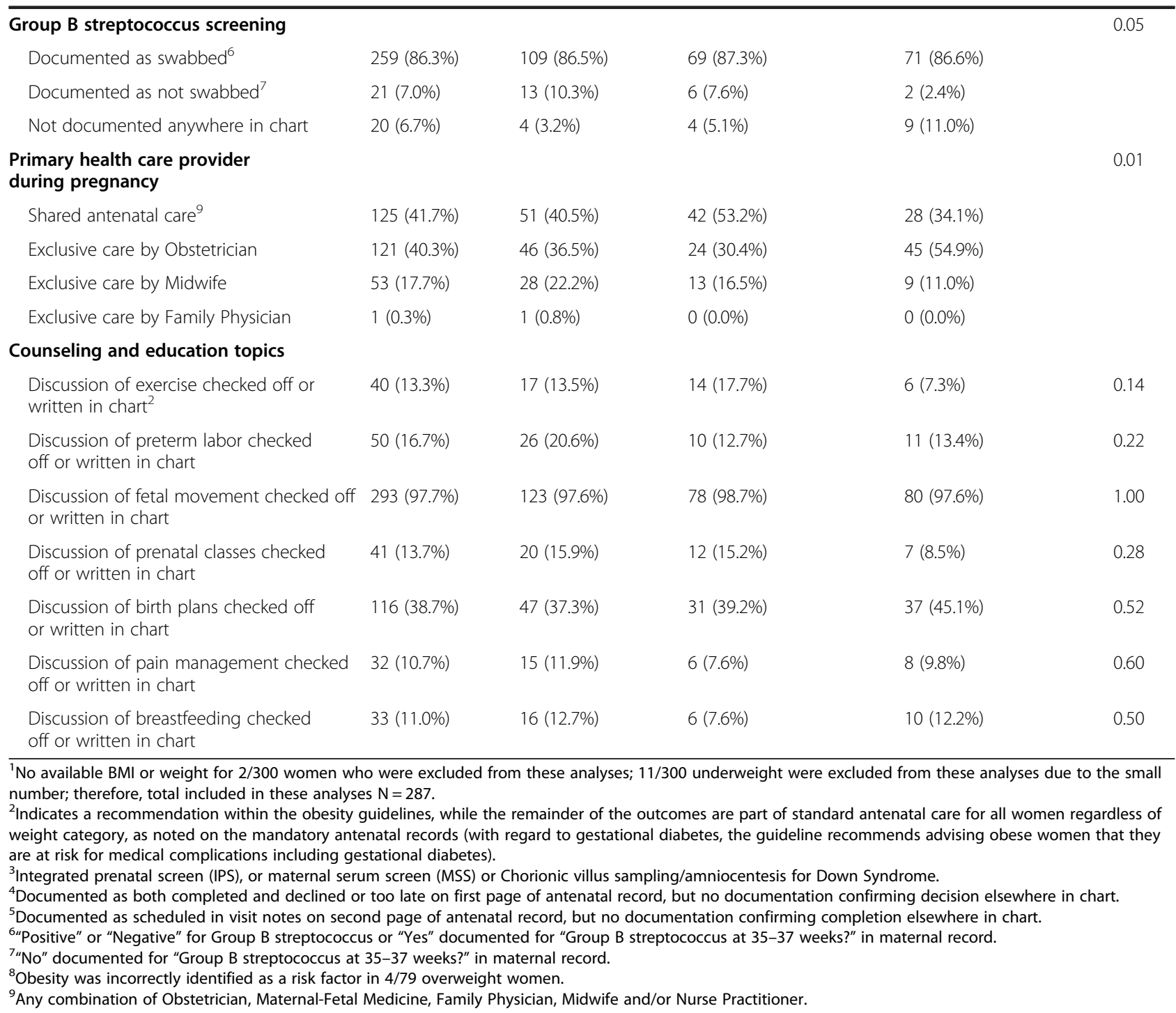

demonstrated awareness of the guideline by recommending the correct amount of weight gain for pregnant women [32].

Beyond knowledge translation, to address the suboptimal rates of documentation that we found in this study, there are a number of diverse, innovative approaches which could be employed, including use of electronic medical records, and patient involvement. Electronic medical records could, for instance, automatically calculate BMI after height and weight were entered, and could prompt care providers to discuss appropriate weight gain. Such automated, computerized reminders been found to be effective for improving consistency of routine practices [33]. The potential beneftis of electronic medical records, particularly in obstetrics, has been emphasized: "Obstetrics is an ideal speciality for both the implementation and evaluation of the effectiveness of a paperless record. It is a well-defined field with a relatively standard course of care for a common condition, although is challenged by the diversity of providers (e.g., obstetricians, midwives, family physicians, nurses). Communication among providers is a key element in ensuring quality care, because all patients have their care transferred from outpatient to inpatient settings and back and between different providers, and patients may be cared for by different providers" [34]. Alternately, since much of obstetrical care involves young, healthy women, engaging them to a much larger extent in their care including self-documentation in their charts, is a realistic potential step. Indeed, this approach has been effectively utilized in group prenatal care models in which women describe their preference for sharing ownership of care through increased involvement in weighing themselves, taking their own blood pressure, and charting in their medical record [35]. Self-documentation may have 
other benefits, such as more complete data than is provided by health care workers, as has been noted in the case of some aspects of care documented by parents whose newborns were admitted to an intensive care unit [36].

Appropriate documentation is an important feature of quality health care, [37] managing risk and medical liability [38]. It has been advocated that "there must be a disciplined approach to documentation" [38]. Risk management recommendations include thorough documentation of the past obstetrics history for instance, for pediatricians examining neurologic impairment in newborns [39] and it would be even more important to have complete information about past obstetrics history in obstetric care providers' charts. Improvement of documentation might occur through medical informatics, which The Institute of Medicine's report To Err is Human [40] suggested might decrease medical errors and enhance patient safety.

A main strength of our study is that we did not rely solely on the Antenatal Record Forms, but used other sources including dictated consultations and physician notes, allowing us to decrease the amount of missing data. A single trained data abstractor performed all of the chart reviews, and while we did not perform doublechecking, this eliminated variation between abstractors. We chose to study variables that were standard of care and/or guideline driven. We deliberately included various types of care providers, including obstetricians, midwives and family physicians to obtain a broad sample of care providers whose time constraints vary widely.

Limitations of the study include the fact that our observations were limited to a single academic tertiary care centre. Within this centre there are both high and low risk births, cared for by all types of antenatal care providers being midwives, family physicians, obstetricians. Previous work has found better documentation in high risk charts [41]. Our study took place at a tertiary care centre that provides care to both low and high risk women; however, despite the fact that obese women have a higher risk of complications including preterm birth, documentation was not better among obese women in our study. We reviewed the hospital charts of the patients, and it is possible that there was additional information in the care providers' office charts although typically all of the contents are faxed to the hospital chart. Another limitation is that our sample size of 300, particularly when broken down into the three weight groups, resulted in some outcomes with small numbers. This may have resulted in false negative associations between some weight categories and some outcomes.

Future research should explore ways of improving documentation, including the impact of electronic documentation, and plans are under way to implement this in our hospital clinics in the near future. Following audit, feedback is an important step to improving care,
[42] and will be our next goal, beginning with grand rounds in our hospital. Further education of care providers about the importance of documentation in general and about the content of guidelines, such as the weight gain guidelines, will be important.

\section{Conclusions}

In conclusion, despite a predominance of excess weight in our region, weight-related issues and other important healthcare issues, were suboptimally documented in the chart. Rates of documentation did not increase across weight categories despite both increasing perinatal risks, and guidelines specifically addressing recommendations related to weight in obese women. These finding are important as there is a need to improve documentation, both for optimal care management, communication and quality assurance, but also for the relevance of record keeping for legal cases as the "silent witness" [38].

\section{Abbreviations}

ACOG: American College of Obstetrics \& Gynecology; SOGC: Society of Obstetricians \& Gynecologists of Canada; BMI: Body Mass Index; CMACE/ RCOG: Centre for Maternal and Child Enquiries/Royal College of Obstetricians and Gynaecologists; GBS: Group Beta Steltococcus status; IPS: Integrated prenatal screen; FTS: First trimester screen; MSS: Maternal serum screen; GCT: Glucose challenge test; GTTL: Glucose tolerance test; ANOVA: Analysis of variance; SD: Standard deviation.

\section{Competing interests}

The authors declare that they have no competing interests'.

\section{Authors' contributions}

SDM and DK conceived the study and designed it, CM and LM participated in the design of the study and performed chart data abstraction, SDM drafted the manuscript and edited it with DK, and all authors approved the final version of the manuscript.

\section{Authors' information}

Dr Sarah McDonald (MD, MSc in Clinical Epidemiology) is a Maternal-Fetal Medicine specialist (high risk obstetrician) and Associate Professor in the Department of Obstetrics and Gynecology at McMaster University. As a Clinician-Scientist her salary is supported by a Canadian Institute of Health Research New Investigator Award. Her research in perinatal epidemiology focuses on weight-related issues during pregnancy and the postpartum period, and on related health services. Dr Dawn Kingston, RN, PhD, is an Assistant Professor in the Faculty of Nursing University of Alberta. Her research program focuses on antenatal and postnatal depression and anxiety, and addressing their health services issues.

\section{Acknowledgments}

Sarah D McDonald is supported by a Canadian Institute of Heath Research (CIHR) New Investigator Award \# CNI 95357. CIHR had no role in the design and conduct of the study; collection, management, analysis, and interpretation of the data; and preparation, review, or approval of the manuscript.

\section{Author details}

'Division of Maternal-Fetal Medicine, Departments of Obstetrics \& Gynecology and Diagnostic Imaging and Clinical Epidemiology \& Biostatistics, McMaster University, 1280 Main St. West, HSC 3N52B, Hamilton, ON L8S4K1, Canada. ${ }^{2}$ Department of Obstetrics, Gynecology1280 Main St. West, HSC 3 N52, Hamilton, ON L8S4K1, Canada. ${ }^{3}$ Faculty of Health Sciences, Department of Obstetrics, Gynecology1280 Main St. West, HSC 3 N52, Hamilton, ON L8S4K1, Canada. ${ }^{4}$ Level 3, Edmonton Clinic Health Academy, University of Alberta, 1140587 Avenue, Edmonton, Alberta T6G 1C9, Canada. 
Received: 28 November 2013 Accepted: 28 May 2014

Published: 13 June 2014

\section{References}

1. Wilkinson SA, Stapleton H: Overweight and obesity in pregnancy: the evidence-practice gap in staff knowledge, attitudes and practices. Aust N Z J Obstet Gynaecol 2012, 52:588-592.

2. Management of Women with Obesity in Pregnancy: CMACE/RCOG Joint Guideline. UK: RCOG Press; 2010

3. Salihu HM, Lynch O, Alio AP, Liu J: Obesity subtypes and risk of spontaneous versus medically indicated preterm births in singletons and twins. Am J Epidemiol 2008, 168:13-20.

4. Roman H, Goffinet F, Hulsey TF, Newman R, Robillard PY, Hulsey TC: Maternal body mass index at delivery and risk of caesarean due to dystocia in low risk pregnancies. Acta Obstet Gynecol Scand 2008, 87:163-170.

5. Savitz DA, Dole N, Herring AH, Kaczor D, Murphy J, Siega-Riz AM, Thorp JM Jr, MacDonald TL: Should spontaneous and medically indicated preterm births be separated for studying aetiology? Paediatr Perinat Epidemiol 2005, 19:97-105.

6. Chu SY, Callaghan WM, Kim SY, Schmid CH, Lau J, England LJ, Dietz PM: Maternal obesity and risk of gestational diabetes mellitus. Diabetes Care 2007, 30:2070-2076.

7. McDonald SD, Han Z, Mulla S, Beyene J, on behalf of the Knowledge Synthesis Group: Overweight and obesity in mothers and risk of preterm birth and low birth weight infants: a systematic review and metaanalyses. BMJ 2010, 341:c3428. doi:10.1136/bmj.c3428.

8. Nelson W, Moser RP, Gaffey A, Waldron W: Adherence to cervical cancer screening guidelines for U.S. women aged 25-64: data from the 2005 Health Information National Trends Survey (HINTS). J Womens Health (Larchmt) 2009, 18:1759-1768.

9. Ostbye T, Taylor DH Jr, Yancy WS Jr, Krause KM: Associations between obesity and receipt of screening mammography, Papanicolaou tests, and influenza vaccination: results from the Health and Retirement Study (HRS) and the Asset and Health Dynamics Among the Oldest Old (AHEAD) Study. Am J Public Health 2005, 95:1623-1630.

10. Amy NK, Aalborg A, Lyons $P$, Keranen L: Barriers to routine gynecological cancer screening for White and African-American obese women. Int J Obes (Lond) 2006, 30:147-155.

11. Colman L, Cannon C, Lofsky S, Nwaesei CPK, Reducka K, Wilson K: A Guide to the 2005 Revised Ontario Antenatal Record. Ontario Medical Association (OMA) Antenatal Record Committee. Toronto, ON, Canada: OMA, Health Policy Department; 2006.

12. American College of Obstetricians and Gynecologists: ACOG Committee Opinion number 315, September 2005. Obesity in pregnancy. Obstet Gynecol 2005, 2005(106):671-675

13. Davies GA, Maxwell C, McLeod L, Gagnon R, Basso M, Bos H, Delisle MF, Farine D, Hudon L, Menticoglou S, Mundle W, Murphy-Kaulbeck L, Oullet A, Pressey T, Roggensack A, Leduc D, Ballerman C, Biringer A, Duperron L, Jones D, Lee LS: SOGC Clinical Practice Guidelines: Obesity in pregnancy. No. 239, February 2010. Int J Gynaecol Obstet 2010, 110:165-173.

14. Delaney M, Roggensack A, Leduc DC, Ballermann C, Biringer A, Delaney M, Dontigny L, Gleason TP, Shek-Yn LL, Martel MJ, Morin V, Polsky JN, Rowntree C: Guidelines for the management of pregnancy at $41+0$ to $42+$ 0 weeks. J Obstet Gynaecol Can 2008, 30:800-823.

15. (IOM) Institute of Medicine: National Research Council. Weight Gain During Pregnancy: Reexamining the Guidelines. In Committee to Reexamine IOM Pregnancy Weight Guidelines. Edited by Rasmussen KM, Yaktine AL. Washington, DC: The National Academies Press; 2009.

16. Health Canada: Canadian Gestational Weight Recommendations. 2010. Accessed at http://www.hc-sc.gc.ca/fn-an/nutrition/prenatal/qa-gest-gros-qreng.php on August 2, 2012

17. Fell DB, Joseph KS, Dodds L, Allen AC, Jangaard K, den HM V: Changes in maternal characteristics in Nova Scotia, Canada from 1988 to 2001. Can J Public Health 2005, 96:234-238.

18. Robinson HE, O'connell CM, Joseph KS, McLeod NL: Maternal outcomes in pregnancies complicated by obesity. Obstet Gynecol 2005, 106:1357-1364.

19. National Institute for Health Care Excellence (NICE): NICE Pathways Antenatal Care/Routine Care for all Pregnancy Women. London (UK): National Institute for Health Care Excellence (NICE); 2013.

20. The American College of Obstetricians and Gynecologists: ACOG Antepartum Record, Vs 5. Washington DC: American College of Obstetricians and Gynecologists; 2003.
21. McDonald SD, Pullenayegum E, Bracken K, Chen AM, McDonald H, Malott A, Hutchinson R, Haley S, Lutsiv O, Taylor V, Good C, Hutton EHutchinson R, Haley S, Lutsiv O, Taylor V, Good C, Hutton E: Comparison of midwifery, family medicine and obstetric patients' understanding of weight gain during pregnancy: a minority of women report correct counseling. J Obstet Gynaecol Can 2012, 34:129-135.

22. What is midwifery Care?. Hamilton, Ontario, Canada: The Hamilton Midwives; 2011. http://www.hamiltonmidwives.ca/Whatismidwifery.htm. (accessed Jan 2, 2011).

23. Community Midwives of Hamilton. Hamilton, Ontario, Canada: Community Midwives of Hamilton; 2011. (www.communitymidwivesofhamilton.com/) accessed Jan 22011

24. Peoples-Sheps MD, Kalsbeek WD, Siegel E, Dewees C, Rogers M, Schwartz R: Prenatal records: a national survey of content. Am J Obstet Gynecol 1991, 164:514-521.

25. Cogswell ME, Scanlon KS, Fein SB, Schieve LA: Medically advised, mother's personal target, and actual weight gain during pregnancy. Obstet Gynecol 1999, 94:616-622.

26. Moore Simas TA, Doyle Curiale DK, Hardy J, Jackson S, Zhang Y, Liao X: Efforts needed to provide Institute of Medicine-recommended guidelines for gestational weight gain. Obstetrics \& Gynecology 2010, 115:777-783.

27. Grimshaw JM, Thomas RE, MacLennan G, Fraser C, Ramsay CR, Vale L, Whitty $P$, Eccles MP, Matowe L, Shirran L, Wensing M, Dijkstra R, Donaldson C: Effectiveness and efficiency of guideline dissemination and implementation strategies. Health Technol Assess 2004, 8:iii-72.

28. Cabana MD, Rand CS, Powe NR, Wu AW, Wilson MH, Abboud PA, Rubin HR: Why don't physicians follow clinical practice guidelines? A framework for improvement. JAMA 1999, 282:1458-1465.

29. Cochrane L, Olson CA, Murray S, Dupuis M, Tooman T, Hayes S: Gaps between knowing and doing: understanding and assessing the barriers to optimal health care. J Contin Educ Health Prof 2007, 27:94-102.

30. Chaillet N, Dube E, Dugas M, Audibert F, Tourigny C, Fraser WD, Dumont A: Evidence-based strategies for implementing guidelines in obstetrics: a systematic review. [Review] [71 refs]. Obstetrics \& Gynecology 2006, 108:1234-1245.

31. Ubbink DT, Guyatt GH, Vermeulen H: Framework of policy recommendations for implementation of evidence-based practice: a systematic scoping review. BMJ Open 2013, 3,e001881. doi:10.1136/ bmjopen-2012-001881.

32. Lutsiv O, Bracken K, Pullenayegum E, Sword W, Taylor VH, McDonald SD: Little congruence between health care provider and patient perceptions of counselling on gestational weight gain. J Obstet Gynaecol Can 2012, 34:518-524.

33. Grimshaw JM, Shirran L, Thomas R, Mowatt G, Fraser C, Bero L, Grilli R, Harvey E, Oxman A, O'Brien MA: Changing provider behavior: an overview of systematic reviews of interventions. Med Care 2001, 39:||2-||45.

34. Bernstein PS, Farinelli C, Merkatz IR: Using an electronic medical record to improve communication within a prenatal care network. Obstet Gynecol 2005, 105:607-612.

35. Kennedy HP, Farrell T, Paden R, Hill S, Jolivet R, Willetts J, Rising SS: "I wasn't alone"-a study of group prenatal care in the military. J Midwifery Womens Health 2009, 54:176-183.

36. Blomqvist YT, Rubertsson C, Nyqvist KH: Parent-infant skin-to-skin contact; How do parent records compare to nurse records? Acta Paediatr 2011, 100:773-775.

37. Hicks TA, Gentleman CA: Improving physician documentation through a clinical documentation management program. Nurs Adm Q 2003, 27:285-289.

38. Donn SM: Medical liability, risk management, and the quality of health care. Semin Fetal Neonatal Med 2005, 10:3-9.

39. Physician Insurers Association of America: Neurologic Impairment in Newborns. Rockville, MD: PIAA Press; 2002.

40. Institute of Medicine: To Err is Human: Building a Safer Health System. Washington, D.C.: National Academy Press; 2000.

41. Handler A, Rankin K, Rosenberg D, Sinha K: Extent of documented adherence to recommended prenatal care content: provider site differences and effect on outcomes among low-income women. Matern Child Health J 2012, 16:393-405.

42. Kongnyuy EJ, Uthman OA: Use of criterion-based clinical audit to improve the quality of obstetric care: A systematic review. [Review] [38 refs]. Acta Obstet Gynecol Scand 2009, 88:873-881.

doi:10.1186/1471-2393-14-205

Cite this article as: McDonald et al:: Documentation of guideline adherence in antenatal records across maternal weight categories: a chart review. BMC Pregnancy and Childbirth 2014 14:205. 